\title{
Fatigue Life Prediction of Welded Joint by Microstructure-based Simulation
}

\author{
Takayuki Shiraiwa ${ }^{1, *}$, Fabien $^{\text {Briffod }}{ }^{1}$, and Manabu Enoki $^{1}$ \\ ${ }^{1}$ Department of Materials Engineering, The University of Tokyo, 7-3-1 Hongo, Bunkyo-ku, Tokyo 113-8656, Japan
}

\begin{abstract}
This paper proposes a numerical framework to predict fatigue life on welded joints by integrating several computational techniques. The framework consists of five steps: i) materials properties estimation; ii) welding simulation using thermo-mechanical finite element method; iii) macroscopic stress field analysis under cyclic loading; iv) mesoscopic stress field analysis using crystal plasticity finite element method (CPFEM); v) analysis of fatigue crack growth. The total number of cycles to failure is eventually obtained by the sum of initiation life calculated by CPFEM and propagation life calculated by X-FEM. A fatigue life of butt joint is evaluated by the proposed method. The results demonstrated the possibility of evaluating the fatigue life and its scattering by the proposed framework.
\end{abstract}

\section{Introduction}

Development of new materials often takes considerable time and cost to evaluate its performances. A huge amount of fatigue tests are required to ensure the fatigue performance. Against such a background, various numerical methods to predict properties related to fatigue in the welded joints have been proposed. Crystal plasticity simulations can take account for the physical deformation mechanisms and have attracted considerable attention for predicting fatigue problems in recent years [1-5]. Also, the X-FEM is used to calculate the crack path $[6,7]$. The objective of this research is to develop a comprehensive framework based on these computational techniques for predicting the fatigue performance of the welded joint.

\section{Method}

Overview of the prediction method is shown in Fig. 1. The first step is estimation of several material properties. The density, specific heat, thermal conductivity, coefficient of thermal expansion, Young's modulus, Poisson's ratio, continuous cooling transformation (CCT) diagram and yield stress were estimated for each phase from the chemical composition. In the second step, the residual stress and the microstructure distribution are analysed. A finite element model was automatically created by the shape parameters (thickness of plate, toe radius and so on). The heat input was defined by the Goldak's model [8]. In the phase transformation analysis, Koistinen-Marburger model and Kolomogorov-JohnsonMehl-Avrami model [9-12] were used. Based on the cooling rate, the austenite grain size and hardness were calculated according to the empirical equations [13]. In the third step, macroscopic stress analysis was performed. A finite element model was divided into 10 regions, and different stress-strain curves were given to each region. The fourth step is analysis of mesoscopic stress field using CPFEM. The finite element model was cut out around the highest stress location in the macroscopic model. The synthetic grains were created by a tessellation method [5]. To simulate the elasticplastic deformation behaviour, the phenomenological constitutive law $[14,15]$ was used within the Düsseldorf advanced material simulation kit (DAMASK) [16]. The number of cycles for crack initiation was analysed by Tanaka-Mura model [17],

$$
N_{\mathrm{i}}=\frac{8 G W_{\mathrm{s}}}{\pi(1-v) d\left(\Delta \tau^{\alpha}-2 \tau_{\mathrm{c}}^{\alpha}\right)^{2}},
$$

where $G$ is the shear modulus, $W_{\mathrm{s}}$ is the fracture surface energy per unit area and $d$ is the slip band length. In the last step, the initial crack was introduced into the macroscopic model. The Paris' law [18] was used to predict the crack growth rate where the stress intensity factor was calculated by the virtual crack closure method [19] and the constants [20]. 


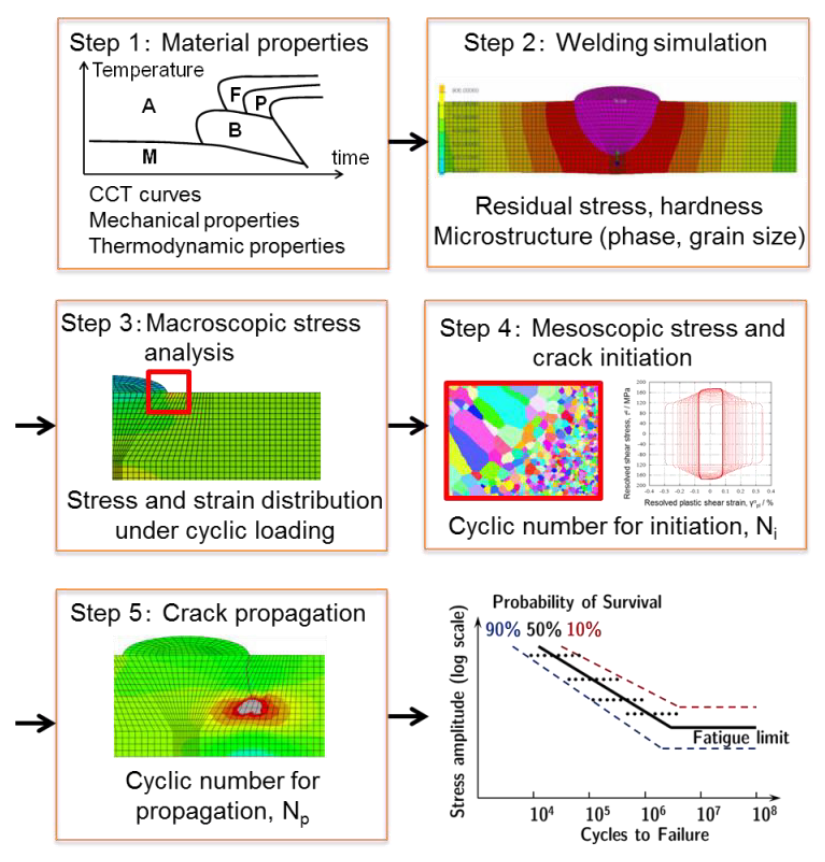

Fig. 1 Proposed method for fatigue life prediction of welded joints.

\section{Results and discussion}

The thermal and mechanical properties including CCT diagram were successfully calculated by JMatPro. Using these properties, the welding simulation was performed. The distribution of volume fraction of martensite, maximum temperature, Vickers hardness, prior austenite grain size, and residual stress are shown in Fig. 2. The element with the highest value of maximum principal stress was record to identify the stress concentration part. According to the shape at the stress concentration part, synthetic grain morphology was generated. An example of cumulative plastic shear strain distribution is depicted in Figure 3. The cumulative shear plastic strain archived a high value around the weld toe, and the plastic strain showed heterogeneous distribution. The crack initiation life was calculated by equation (1) for each grain, and the crack is assumed to initiate at the slip system with the minimum initiation life. As shown in Fig. 4, the crack growth path was calculated by X-FEM. The calculation of X-FEM did not converge after the crack length exceeded one-third of the plate thickness. Thus, the number of cycles for crack growth was determined at the one-third of the plate thickness. The total fatigue life was obtained by summing the initiation and propagation life.

The results were plotted in Fig. 5. The solid line shows the fatigue design curves of the class $\mathrm{C}$ recommended by Japanese society of steel construction [20]. The simulation provided the longer life than literature values. This is because the simulation assumed the smooth weld toe. Even if the geometry improvement is carried out, there remain a complex shapes or small defects not detected by NDT. They may induce stress concentration in the actual situation. The effect of stress concentration due to surface roughness will be discussed.
In a different perspective, the scattering in fatigue life decreased with increasing the stress level. In the low cycle region, the most of the lifetime is spent on crack growth and the effect of microstructure is small. On the other hand, large scattering appeared under the low stress level. In order to consider the effect of crack initiation on the scattering, the ratio of crack initiation life to the total fatigue life was evaluated as shown in Fig. 6. The proportion of initiation life occupying fatigue life increased with the total fatigue life. This indicated that the scattering in fatigue life is mainly due to the crack initiation. Lawrence et al.[21], Tagaki et al. [22] and Lautrou et al. [23] measured crack initiation life in weld joints by using various experimental methods. The results of these experimental observations are also shown in Figure 6. In the experimental results, the same tendency was observed. The difference in absolute value of $\mathrm{Ni} / \mathrm{Nf}$ is due to the different definition of the crack initiation between the experiment and simulation. In the experiment, the initiation is determined when a detectable crack (about $1 \mathrm{~mm}$ ) is found. In the simulation, the initiation is the number of cycles required to generate a crack in one grain. Due to this difference, the simulation predicted the shorter initiation life than the experimental observation. The scattering in the crack initiation life appears to be comparable in the calculations and the experiments. Therefore, the possibility of predicting the scattering of fatigue life based on the proposed method was demonstrated.

In the fatigue crack growth analysis, the scatter due to microstructurally small crack (MSC) should be considered. In addition, it is necessary to validate with experimental data not only at the final step ( $\mathrm{S}-\mathrm{N}$ curve) but also the intermediate steps. Comparison with experimental observation about residual stress and hardness distribution will be discussed.
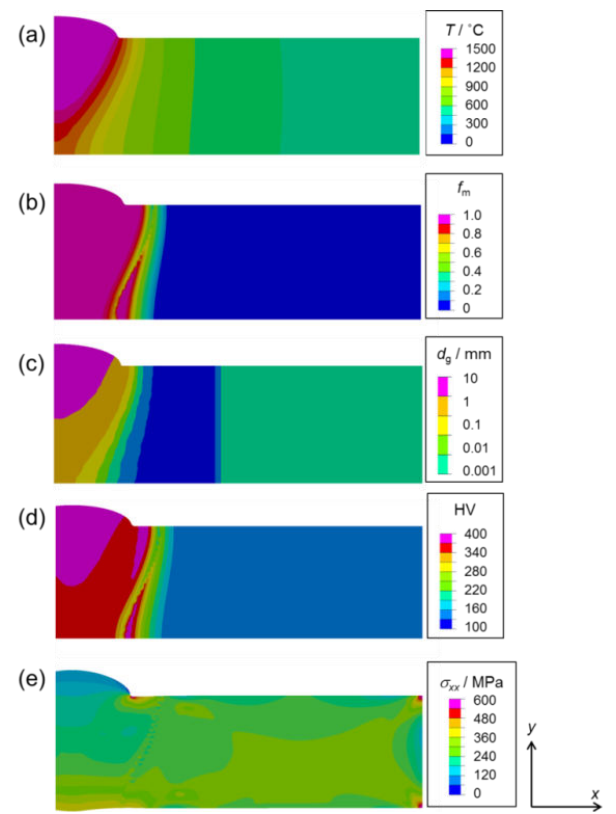

Fig. 2 Distribution of (a) maximum temperature during welding, (b) volume fraction of martensite, (c) prior austenite grain size, (d) Vickers hardness, (e) residual stress of butt joint. 


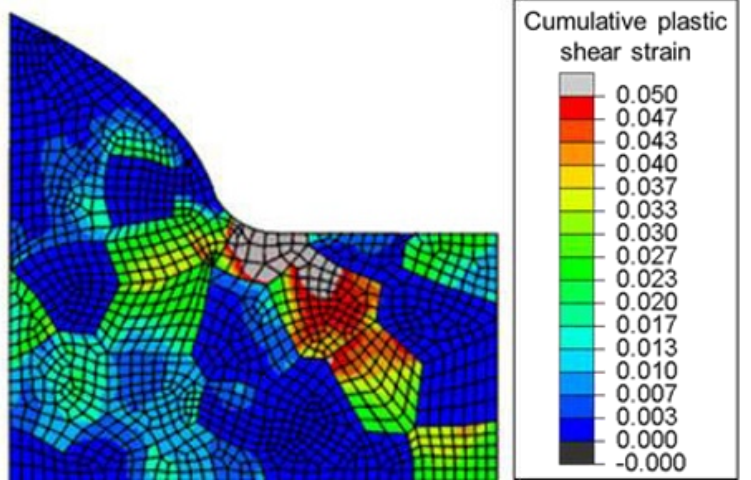

Fig. 3 Example of cumulative plastic shear strain in each slip system $(\Delta \sigma=300 \mathrm{MPa})$

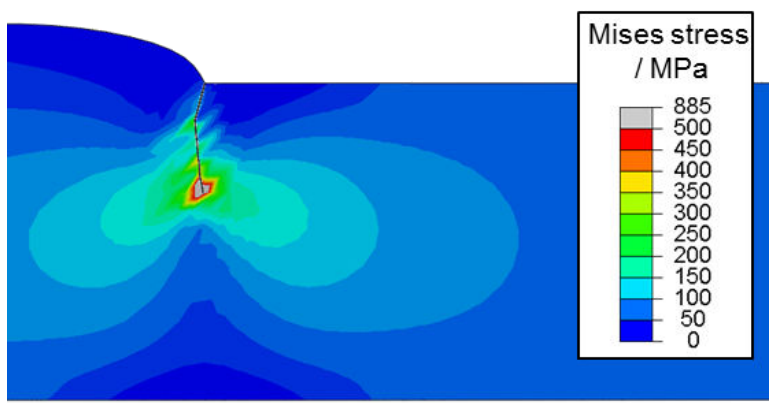

Fig. 4 Example of crack growth path calculated by X-FEM.

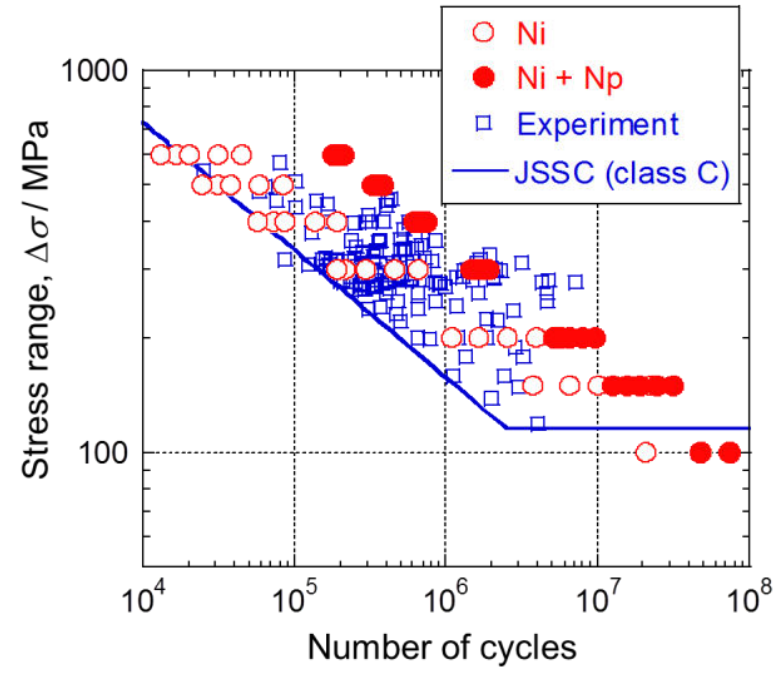

Fig. 5 Predicted fatigue life and the fatigue design curve recommend by JSSC[20].

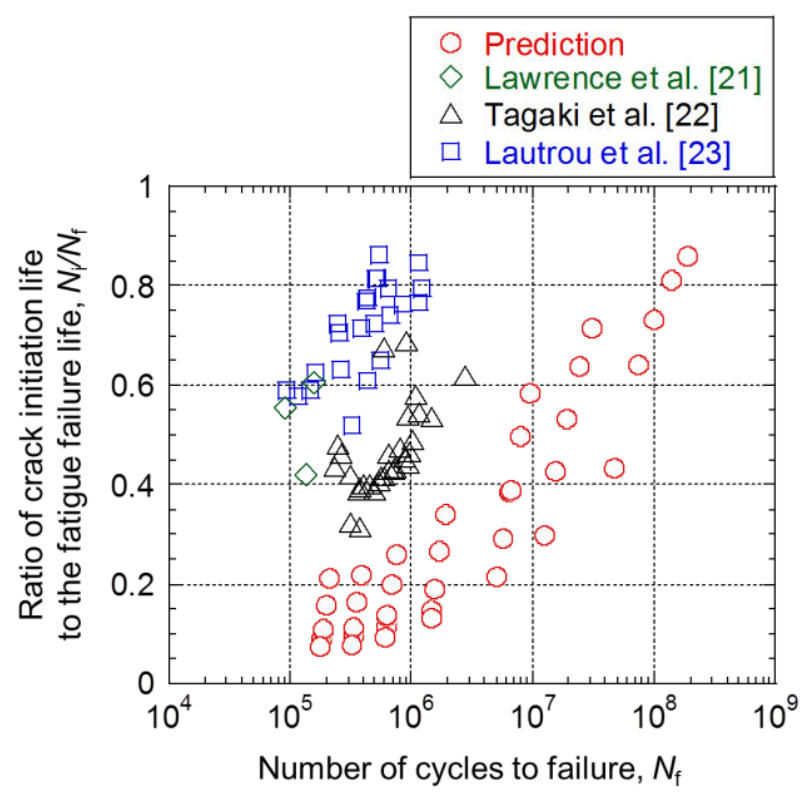

Fig. 6 Ratio of crack initiation life to the total fatigue life.

\section{Conclusion}

In this paper, a comprehensive framework for the fatigue life prediction in welded structures was proposed and applied to the butt welding joint with low carbon steels. The distributions of grain size, phase, hardness and residual stress were calculated by heat transfer, phase transformation and thermal-elastic-plastic analysis. The macroscopic model was created by the residual stress and hardness distribution, and the stress field analysis was performed under cyclic loading. The mesoscopic stress field was calculated by CPFEM and the crack initiation life was estimated by the Tanaka-Mura model. The total fatigue life was calculated by summing the initiation life and propagation life. A more sophisticated analysis would be required for reflecting the effect of surface roughness, the complicated crack morphology at weld toe and microstructurally small crack growth.

\section{References}

1. F. Roters, P. Eisenlohr, L. Hantcherli, D.D. Tjahjanto, T.R. Bieler, D. Raabe, Acta Mater., 58, 1152 (2010)

2. P. Shanthraj, P. Eisenlohr, M. Diehl, F. Roters, Int. J. Plast., 66, 31 (2015)

3. D.L. McDowell, F.P.E. Dunne, Int. J. Fatigue, 32, 1521 (2010)

4. F. Briffod, T. Shiraiwa, M. Enoki, Mater. Trans., 57, 1741 (2016)

5. F. Briffod, T. Shiraiwa, M. Enoki, Mater. Sci. Eng., A, 695, 165 (2017)

6. Y. Xu, H. Yuan, Eng. Fract. Mech., 76, 165 (2009)

7. X. Ren, X. Guan, Eng. Fract. Mech., 177, 218 (2017)

8. J. Goldak, A. Chakravarti, M. Bibby, Metall. Trans. B, 15, 299 (1984) 
9. A. Kolmogorov, Izvestia Akademia Nauk Serie Mathematica SSSR, 1, 355 (1937)

10. M. Avrami, J. Chem. Phys., 7, 103 (1939)

11. W.A. Johnson, R.F. Mehl, Transactions of the American Institute of Mining and Metallurgical Engineers, 135, 416 (1939)

12. D.P. Koistinen, R.E. Marburger, Acta Metall., 7, 50 (1959)

13. J.B. Leblond, J. Devaux, Acta Metall., 32, 137 (1984)

14. J.W. Hutchinson, Proceedings of the Royal Society of London. A. Mathematical and Physical Sciences, 348, 101 (1976)

15. D. Peirce, R.J. Asaro, A. Needleman, Acta Metall., 31, 1951 (1983)

16. F. Roters, P. Eisenlohr, C. Kords, D.D. Tjahjanto, M. Diehl, D. Raabe, Procedia IUTAM, 3, 3 (2012)

17. K. Tanaka, T. Mura, J. Appl. Mech., 48, 97 (1981)

18. P. Paris, F. Erdogan, Journal of Basic Engineering, 85, 528 (1963)

19. E.F. Rybicki, M.F. Kanninen, Eng. Fract. Mech., 9, 931 (1977)

20. JSSC, Fatigue Design Recommendations for Steel Structures, Giho-do, Tokyo, Japan (2010)

21. F.V. Lawrence, W.H. Munse, Welding Journal, Research Supplement, 52, 221 (1973)

22. N. Tagaki, A. Kondo, K. Yamada, Y. Kikuchi, Journal of Japan Society of Civil Engineers, 324, 151 (1982)

23. N. Lautrou, D. Thevenet, J.Y. Cognard, Fatigue \& Fracture of Engineering Materials \& Structures, 32, 403 (2009) 